\title{
An Evolutionary Explanation for Sex Differences in Nonmarital Breakup Experiences
}

\author{
Tara DeLecce $^{1}$ (D) Glenn Weisfeld ${ }^{1}$
}

Received: 6 August 2015 / Revised: 24 November 2015 / Accepted: 26 November 2015 /

Published online: 14 December 2015

(C) Springer International Publishing 2015

\begin{abstract}
Previous research has extensively studied sex differences in mating strategies such as mate preferences and degree of choosiness and how these affect relationship initiation. Very little research, however, has examined these sex differences and how they may play a role in nonmarital relationship dissolution. The existing literature that does examine nonmarital breakups tends to do so from a clinical perspective and neglects the evolutionary approach. The current study uses self-report data gathered from 392 participants through Mechanical Turk to expand upon the sparse existing literature on nonmarital relationship dissolution from an evolutionary perspective to investigate how sex differences in mating strategies affect breakup processes such as the coping period, emotions experienced, and post-breakup behaviors. Results revealed that women require a longer time period to get over an ex-partner with a good sense of humor and are more likely to make in-person contact with such an ex-partner. For postbreakup emotions, women were significantly more likely to report feeling happy which likely is a reflection of the finding that they were more likely to initiate breakups. Men, on the other hand, were more likely to report feeling sexually frustrated following relationship dissolution. Post-breakup behaviors were predicted by breakup initiator rather than participant gender. Overall, these findings support sexual dimorphism in the value of humor and greater female choosiness even after initial mate selection.
\end{abstract}

Keywords Genderdifferences · Relationship dissolution · Nonmarital breakups · Mating strategies

Breakups are the outcome of the majority of nonmarital romantic relationships. In fact, more than $85 \%$ of Americans report having had at least one romantic relationship dissolve before marriage (Battaglia et al. 1998). Historically, however, the literature has largely neglected

Tara DeLecce

taradelecce@gmail.com

1 Wayne State University, Detroit, MI, USA 
this staple of human nature and instead focused on attraction and relationship initiation (Buss 1989). Additionally, the work that has been done on relationship dissolution is often limited to divorce (Gottman 1994; Lavner and Bradbury 2012) and much of it focuses significantly more on the effects of divorce on children produced from the marriage rather than focusing on the divorce itself (Buchanan et al. 1996; Cherlin et al. 1991; Wallerstein et al. 2013).

In the last few decades, however, it has become more common to find studies focusing on nonmarital relationship termination. Specifically, the focus has often been on predictors of impending termination such as perceptions of alternatives, unequal degrees of commitment to relationship, and lack of support from one's social circle for the relationship (Hill et al. 1976; Le et al. 2010). There has been some attention paid to the coping process that follows a breakup. The studies that have addressed this phenomenon have approached it primarily from a clinical or health psychology perspective (Field 2011; Field et al. 2010). and a very paltry amount of research has examined coping with a breakup from an evolutionary perspective (Morris et al. 2015; Perilloux and Buss 2008; Shackelford et al. 2002). The current study examines how coping with a romantic breakup is influenced by evolutionarily based sex differences in mating psychology. The following sections will describe such sex differences.

\section{Evolutionarily-Based Sex Differences in Mating Psychology}

Although there are similarities between men and women's preferences in a mate, sex differences in mate preferences during initial choosing of a mate have been identified cross-culturally. Specifically, men prefer women who are young and physically attractive as this signals fertility and reproductive value, while women prefer men who have good financial prospects and are of high social status as this signals potential to be a good provider for her and her children (Buss 1989; Toro-Morn and Sprecher 2003).

Men and women differ not only in their preferences for certain characteristics in a mate, they differ in their degree of overall choosiness when seeking a mate as well. This difference can be traced back to parental investment theory (Trivers 1972) which states that the sex that has the greater minimal parental investment tends to be choosier. In humans (and most mammals), the female's minimal investment in offspring includes gestation and lactation, while the male's minimal investment in offspring is a single copulation. Therefore, women have the larger minimal investment which makes them have lower reproductive potential and consequently makes them choosier when selecting a mate. Although intra-sex variations do occur, this theory of women's generally greater choosiness has received considerable empirical support (Buss and Schmitt 1993; Kenrick et al. 1993; Woodward and Richards 2005; Todd et al. 2007).

Even after initial mate selection, men and women have been found to differ in mate retention tactics. According to a study on mate retention behaviors in married couples, men are more likely to use submission or intrasexual threats, while women are more likely to use the tactic of verbal signals of possession (Buss and Shackelford 1997). Men have also been known to use more physical threats and actual violence against their partner (intersexual violence) in response to possible threats to the relationship which are typically infidelity or desertion (Daly and Wilson 1988). Imagined or real infidelity/desire to leave is also the number one motive for husbands to kill their wives (uxoricide), which may be an extreme manifestation of mate retention behavior (Daly and Wilson 1988). 


\section{Sex Differences in Mating Psychology Applied to Breakups}

Breakup Initiation and Emotions These sex differences are just now beginning to be applied to psychological processes involved in nonmarital breakups. The greater choosiness of women appears to have an influence on breakups as it has been found that not only do men fall in love faster than women, but they also report more romanticism (Hill et al. 1976). Women, on the other hand, seem to take longer to fall in love, report falling out of love more often than men, and initiate breakups at a higher rate than men (Hill et al. 1976). This was corroborated by the finding that men tend to report more sadness, grief, and despair following a breakup than women (Rubin et al. 1981). In a different study examining self-report data from men and women who initiated breakups, it was found that women tend to list more reasons for a breakup than men do (Baxter 1986). Taken together, these findings support parental investment theory in that women have higher costs associated with a poor mate choice so it would be adaptive for them to be more vigilant of signals of possible incompatibility or a decline in mate value as the relationship unfolds.

Women's overall greater propensity to initiate breakups, however, has been met with contradictory findings. In a study by Perilloux and Buss (2008). it was found that not only were men more likely to initiate a breakup, but were more likely to report feeling indifferent or relieved as a result of a breakup. On the other hand, women were more likely to report feeling sad, confused, and scared in response to a breakup. The authors of the study speculate that this was due to the college environment; men at this age might have more to gain from a short-term mating strategy as they are given potential access to hundreds of young, fertile women at a university, while women might be more upset as they are near their peak mate value at this time and it would be considered more costly for them to lose a mate who was high in quality. Similar findings were reported in a study measuring breakup distress in college students in that women, compared to men, reported higher levels of stress and depression following a breakup (Field et al. 2010). However, the study by Hill and colleagues (1981) involves a college environment as well which challenges this explanation. Such contradictory arguments make more research into this area necessary.

Post-Breakup Behaviors Mate retention behaviors employed once a relationship has dissolved resemble tactics used while relationships are still intact. These have been coined "unwanted pursuit behaviors" and are displayed by both sexes (Duntley and Buss 2012). Specifically, men are more likely to be aggressive in their tactics by going to places where their ex-partner is, threatening or physically abusing their expartner, while women are more likely to leave unwanted phone messages (Perilloux and Buss 2008). It has also been suggested that women can be prone to aggression as well, but it is not as notable due to its milder nature (Archer 2000). One study found that women more often than men engaged in mild aggression in the form of slapping (Williams and Frieze 2005). Behaviors typically established as more common for women include cyberstalking (Spitzberg and Hoobler 2002) and frequently texting their ex-partner (see Duntley and Buss 2012, for review on unwanted pursuit behaviors/stalking). Such sex differences in the intensity of aggression in these unwanted pursuit behaviors are likely a by-product of higher male testosterone levels (Baumeister et al. 2001). 
Instead of efforts to reconnect with an ex-partner, individuals involved in recent breakups may want to immediately establish a new relationship with someone else. Motivation to form a new relationship can be adaptive in that acquiring a new partner can buffer the drop in status that may have occurred from an ex-partner's abandonment. This would be amplified if the new partner is of higher quality than the ex-partner, in which case the upgrade in partner quality is accompanied by other reproductive benefits such as "good genes" and/or resources. In order to facilitate this process, sex differences in methods used to do so might be expected. For instance, women who just got out of a relationship would be more likely to invest in appearance enhancement to attract a new mate as physical attractiveness is more important to men. Perilloux and Buss (2008) found that women more than men reported more shopping and beauty enhancement as a reaction to a breakup. Men, on the other hand, would be more likely to show off their financial status by spending money to attract a new mate. This is likely to be a better strategy for men as women are more interested in a mate with good financial prospects (Buss 1989).

Ex-Partner Characteristics Since men seem to be more concerned with physical attractiveness in a mate and women seem to be more concerned about earning potential in a mate during relationship formation, it is likely that these preferences remain important throughout a relationship, including during relationship dissolution. One piece of evidence supporting this notion is that a positive correlation has been documented between male mate-guarding behavior and partner attractiveness (Buss 2002). Partner attractiveness also affects shifts in mate-guarding behavior based on the ovulatory cycle such that men whose partners are relatively less attractive intensify mate-guarding during ovulation while very attractive women report intense mateguarding by their partners consistently throughout their cycles (Haselton and Gangestad 2006). For women, they too engage in mate-guarding behavior, and the intensity of this behavior is positively correlated with their partner's income and status striving (Buss and Shackelford 1997). Based on these findings, it is logical to speculate that these partner characteristics affect aspects of a breakup once a relationship has officially dissolved (although this has not been tested to our knowledge). As men seem to view physically attractive women as more valuable partners, they may have a more intense reaction to the loss of such a high quality

mate. For women, they may have a stronger reaction to the loss of a partner with good earning potential and status as this is what they value in a partner. A loss of a high quality partner may cause intense emotions and thus possibly motivate behaviors to try to win back the partner.

\section{Hypotheses of the Current Study}

Given these sex differences based on evolutionary theory, the current study was designed to investigate them in the context of breakups. The purpose of this study was multi-faceted and aimed to 1) clarify sex differences in likelihood of initiating a breakup as well as sex differences in breakup emotions, 2) replicate previous findings (Perilloux and Buss 2008) on sex differences in post-breakup behaviors, and 3) go beyond previously tested ideas to see if characteristics of one's ex-partner would affect 
breakup coping period. The following sections will explain these three categories of predictions in more detail.

1. Sex differences in breakup initiation and post-breakup emotions. As far as sex differences in the likelihood of simply initiating a breakup are concerned, the existing literature is inconsistent about whether men or women are more likely to initiate breakups (see Morris et al. 2015 vs. Perilloux and Buss 2008) as well as which sex is more likely to feel more depressed and overall distressed (see Field et al. 2010 vs, Rubin et al. 1981). However, there seems to be a preponderance of literature citing females as having a higher propensity to initiate breakups (Baxter 1986; Hill et al. 1976; Morris et al. 2015) which is why we hypothesized that women will be more likely than men to initiate a breakup. This is also in accordance with parental investment theory and greater female choosiness.

To be more specific about emotional reactions, various affects were to be examined in order to reveal possible sex differences. It was predicted that women will be more prone to report internalizing negative emotions such as sadness and guilt. This expectation is more exploratory in nature and due in part to women's tendency to ruminate more than men which tends to involve more self-deprecating thoughts and emotions (Johnson and Whisman 2013). For men, we predicted that they will be more likely to report externalizing negative emotions including jealousy, anger, and desire for revenge. Although such specificity in emotions is rarely examined in breakup scenarios, one study on emotional reactions to breakups did find that men are more likely to experience anger and rage upon being abandoned by their partner (Fisher 2004). The proposed reason being that they are more focused on reactions to a drop in status or blow to one's ego, as men are typically more concerned with their status (von Rueden et al. 2010). Such emotions may motivate men to pursue status-enhancement which would subsequently lead to future mating opportunities (Valentine et al. 2014). Additionally, the experience of sexual frustration could be stronger for men due to their generally greater sex drive which is largely associated with their higher testosterone levels (Baumeister et al. 2001).

However, it was also predicted that men would be more likely to report positive emotions such as happiness, indifference, and relief because their initiation of a breakup would be viewed (by them) as an opportunity to seek out a new partner or partner(s). This experience would be especially satisfying for men's greater desire for sexual variety due to their greater reproductive potential (Schmitt et al. 2001). Women, on the other hand, may experience more negative affects regardless of who initiated the breakup (as noted in previous literature; e. g. Field et al. 2010; Perilloux and Buss 2008) due to the fact that they have lower reproductive value than when they initially attracted their partner, so a large investment in a relationship that eventually fails is more reproductively costly for them.

2. Sex differences in post-breakup behaviors. For behavioral responses centered on sustained contact with an ex-partner, the following predictions are in accordance with previous literature on mate retention behaviors and unwanted pursuit behaviors. We predicted that men will be more likely to use aggressive and/or risky methods for unwanted pursuit behaviors such as physically showing up at places uninvited or 
engaging in threats or actual incidents of verbal and/or physical aggression (Spitzberg et al. 2010; Tjaden and Thoennes 1998). In contrast, women would be more likely to use less aggressive and indirect unwanted pursuit behaviors such as cyberstalking, phone calls, texting, and destroying/vandalizing their ex-partner's property rather than actually threatening and/or assaulting their ex-partner (Duntley and Buss 2012).

For those seeking to attract a new partner rather than try to reconnect with the expartner, there were hypotheses based on previous literature such that women would be more likely to go shopping for clothes and/or focus on appearance enhancement for the purpose of attracting a new mate since men value physical attractiveness (Grammer et al. 2004; Perilloux and Buss 2008). Conversely, men seeking another mate as a reaction to the breakup would be more likely to show off their status and spend money in an effort to display their financial prospects and status in order to attract women who find ability to provision more valuable (Guéguen and Lamy 2012; Janssens et al. 2011).

3. Ex-partner characteristics. Unlike most literature that only focuses on the individual providing self-report data, this is the first study (to our knowledge) that examined how coping with a breakup is influenced by characteristics of the ex-partner. Specifically, we predicted that it will take longer for women to get over (or require a longer coping period for) an ex-partner who was high in ambition. This fits with women's desire for earning potential as men of higher ambition are most likely to have higher earning potential later in life (Buss et al. 2001). Getting an accurate assessment of earning potential in college age samples is difficult since most men do not accumulate appreciable resources until later in life. This would be true even for community samples outside of the college subject pool. Furthermore, this effect would be more pronounced for community-sample, working-class women due to the fact that simply being in college is an honest signal of a man's ambition, while for men who do not go to college there is a lack of an equivalent clear signal. It could be that there are less ambitious or industrious men in such a population, and if a woman loses one of these rare men as her partner, then it is even more costly.

For men, however, we predicted that it will take longer for men to get over (or require a longer coping period for) an ex-partner who was high in physical attractiveness as this is a characteristic more important to men (Buss 1989). It could be speculated that the adaptive value of this longer coping period is to motivate the person to try to re-establish the relationship with a high-quality partner.

\section{Method}

\section{Participants}

Participants were recruited through Mechanical Turk as it has been documented that Mechanical Turk yields a more diverse sample than other online forms of survey administration (Casler et al. 2013) 480 participants were recruited; however, after 
accounting for major amounts of missing data (66 participants only answered the first two or three questions), and 18 participants missing only demographic information (most importantly gender), this resulted in 84 participants being dropped from analyses. Additionally, 4 homosexual participants were removed from analyses (as the evolutionary hypotheses and predictions above only apply to heterosexual mating psychology), and therefore the final sample was 392. There were 181 women, 211 men. Mean age was 31.92 and ranged from 19 to 63 . In terms of ethnicity the sample was $68.3 \%$ Caucasian, $15.1 \%$ Asian, $5.6 \%$ were African American, $4.4 \%$ Hispanic, $1 \%$ Native American, and $1.2 \%$ identified as other. $94.4 \%$ of participants reported to be residing in the United States, $4.8 \%$ in India, $0.3 \%$ in Romania, and $0.5 \%$ in the United Kingdom. The majority of participants had some college level education whether it was at the associate or bachelor's level. Additionally, the most common income level reported was between $\$ 30,000$ and $\$ 50,000$ annually.

\section{Materials}

We expanded upon the instrument used by Perilloux and Buss (2008) to explore the various aforementioned hypotheses regarding participants' most recent breakup. This newly expanded survey, named the Relationship Dissolution Questionnaire (RDQ), consists of five categories. However, not all five categories worth of information were analyzed. The survey opened with items measuring baseline information about the breakup including how long ago the breakup occurred, how long the relationship lasted, and how long it took to get over the breakup (coping period). These items all had answer choices that increased in time increments, for instance time elapsed since breakup ranged from less than a week ago, less than 1 month ago, less than 6 months ago, less than 1 year ago, 1-2 years ago, and over 2 years ago. For the length of relationship, item choices included less than 6 months, 6 months to 1 year, 1-2 years, 3-5 years, and over 5 years. And for the coping period item, choices included less than 2 weeks, 1-3 months, 3-6 months, 6 months to 1 year, more than 2 years, or will never get over it. Additionally, who initiated the breakup (participant or his or her ex-partner) was included as a questionnaire item.

The first category of interest investigated emotions experienced following relationship dissolution. The emotions in question included sadness, anger, fear, confusion, shock, sexual frustration, loneliness, humiliation, jealousy, vengefulness, indifference, happiness, relief, and guilt; these are all emotions measured in the survey by Perilloux and Buss (2008). Levels were all reported via a Likert-type scale ranging from 1 to 10.

Another category focused on the characteristics of the participant as well as the participant's ex-partner (as provided by the participant) such as degree of physical attractiveness, ambition, intelligence, and sense of humor. This section included perceptions of both the participant and his or her ex-partner in order to examine perceptions of degree of matching in relative mate value.

The last category of interest focused on specific behaviors engaged in by both the participant and the participant's ex-partner (as reported by the participant) as a reaction to the breakup as well as which ones were performed most and least frequently. Specific behaviors included avoidance, texting and/or calling the expartner, in-person contact with the ex-partner, appearance enhancement, and showing off financial resources. 
There existed other categories in the RDQ but were not analyzed in the current study. One such category examined specific breakup causes (e.g. infidelity, differences in values, etc.). There was also an open-ended section for any other information participants wanted to disclose that was not covered already; however this did not yield any additional relevant information.

\section{Procedure}

The RDQ was first pilot tested amongst a small sample $(N=10)$ to see how long it took to fill out and to figure out if all items were written in a clear way that did not confuse participants.

Once the pilot testing was completed and the necessary adjustments made to the RDQ, it was administered online via Mechanical Turk. These adjustments were minor and mostly involved slightly changing the wording of some questions. These included making it clear that the survey was meant to refer to participants' most recent breakup, adding potential post-breakup behavior options to choose from regarding online/ technology-related means of contacting an ex, and moving the demographics section from the beginning of the survey to the end (as some research shows that this results in better compliance; Dillman 2007).

\section{Results}

\section{Breakup Initiation}

To test for sex differences in breakup initiator and breakup reasons, an independent samples t-test was run to test for sex differences in overall likelihood of initiating a breakup. The hypothesized sex difference in initiator was obtained as women were more likely to initiate breakups than men $(t(390)=3.98, p<0.001, d=0.40)$. To look at more detail into sex differences in reasons reported for breakups for exploratory purposes, logistic regression was used to calculate the odds that each of the 10 reasons included in the survey was predicted by sex. The alpha level was adjusted for this set of analyses as well with a Bonferroni correction. However, none of these analyses revealed any statistically significant results.

\section{Sex Differences in Emotions}

In order to test for sex differences in emotions experienced, independent samples t-tests were performed with a Bonferroni correction as there were $14 \mathrm{t}$-tests conducted. Additionally, mediation analyses via Baron and Kenny (1986) as well as the Sobel method (Preacher and Hayes 2004) were run to see what factors may or may not mediate sex differences in emotions.

For the 14 independent-samples t-tests the Bonferroni correction adjusted the critical alpha level from 0.05 to 0.004 . Only one sex difference was significant at the 0.004 level, and it was amount of sexual frustration $(t(388)=2.99, p=0.003)$, with men reporting significantly higher sexual frustration than women $(M=4.41$ for males, $M=3.44$ for females). One other sex difference was approaching 
significance, happiness $(t(388)=-2.79, p=0.006)$, with women reporting significantly higher levels of happiness than men $(M=1.76$ for males, $M=2.48$ for females). Generally speaking, there were low levels reported for most emotions; only sadness, anger, confusion, and loneliness had levels above the halfway point of 5 for both genders. For means and standard deviations of other reported emotion levels, refer to Table 1.

To get a better understanding of the sex differences in emotions that were revealed, the following factors were taken into account to see if they affected these results: length of relationship, how long ago the breakup occurred, and who initiated the breakup. Mediation analyses via the Baron and Kenny method as well as the Sobel indirect effect test both revealed that breakup initiator mediated the sex differences found in post-breakup emotions. The Sobel test revealed that for the mediation between the relationship between gender and happiness, Sobel $z=3.74, p<0.001$, indirect effect $=63.20 \%$, and direct effect $=36.80 \%$. For sexual frustration, Sobel $z=-3.08, p=0.002$, indirect effect $=31.27 \%$, and direct effect $=68.73 \%$. The Baron and Kenny-style mediation analyses revealed that the relationship between gender and happiness was fully mediated by breakup initiator. Therefore, women were more likely to report being happy post-breakup because they were initiating breakups to rid themselves of an unsatisfactory partner. Breakup initiator was also revealed to partially mediate the relationship between gender and sexual frustration. In this case, men were more likely to report being sexually frustrated because their ex-partner revoked sexual access. Refer to Fig. 1 for these mediation models.

Table 1 Sex differences in emotions experienced after a breakup

\begin{tabular}{|c|c|c|c|c|}
\hline & \multicolumn{2}{|l|}{ Men } & \multicolumn{2}{|l|}{ Women } \\
\hline & Mean & $\mathrm{SD}$ & Mean & SD \\
\hline Anger & 5.36 & 3.04 & 6.2 & 3.08 \\
\hline Sadness & 7.27 & 2.39 & 7.19 & 2.9 \\
\hline Confusion & 5.88 & 3.03 & 5.63 & 3.25 \\
\hline Shock & 5.48 & 3.04 & 4.8 & 3.41 \\
\hline Vengefulness & 3.32 & 2.98 & 3.58 & 3.29 \\
\hline Happiness & 1.76 & 2.18 & $2.48 \dagger$ & $2.81 \dagger$ \\
\hline Indifference & 2.8 & 2.8 & 2.72 & 3.15 \\
\hline Jealousy & 3.58 & 3.15 & 3.3 & 3.4 \\
\hline Fear & 3.1 & 3.11 & 3.73 & 3.47 \\
\hline Guilt & 3.71 & 3.12 & 3.25 & 3.2 \\
\hline Relief & 2.73 & 2.81 & 3.47 & 3.48 \\
\hline Loneliness & 6.5 & 2.92 & 6.46 & 3.36 \\
\hline Humiliation & 4.09 & 3.39 & 4.11 & 3.6 \\
\hline Sexual Frustration & $4.41 *$ & $3.11 *$ & 3.44 & 3.3 \\
\hline
\end{tabular}

$*<0.004$ (critical 0.05 alpha after Bonferroni correction)

$\dagger<0.007$ (critical 0.10 alpha after Bonferroni correction) 

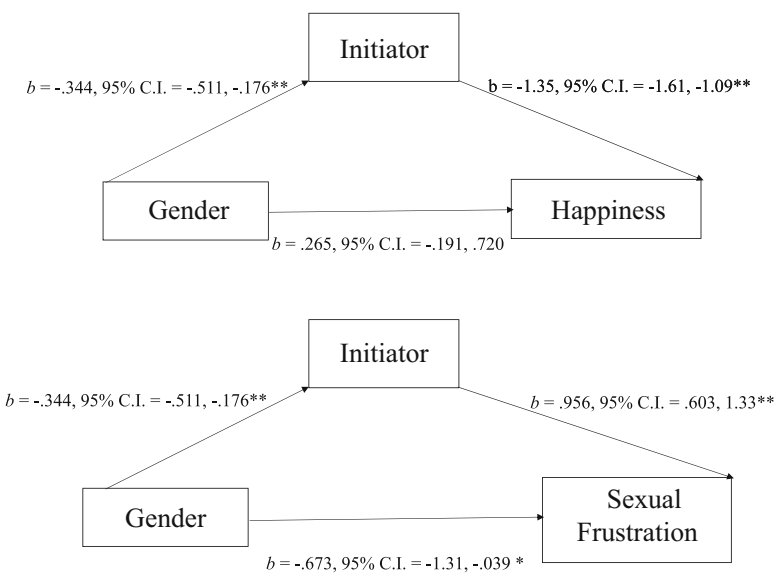

$*=p<.05 ; * *=p<.001$

Fig. 1 These mediation models depict the relationships between gender, breakup initiator, and emotions. Breakup initiator fully mediated the relationship between gender and happiness while it partially mediated the relationship between gender and sexual frustration

\section{Post-Breakup Behaviors}

For post-breakup behaviors, sex differences (along with other variables) were tested using binary logistic regression to predict the odds of whether or not each behavior was engaged in by participants. Because there were many more behaviors inquired about than there were specific predictions for, these analyses were more exploratory in nature and the alpha level was set at 0.01 . These results, therefore, should be interpreted with caution.

Participant gender was not a significant predictor of any of the participants' postbreakup behaviors as originally hypothesized. Additional factors that were examined were breakup initiator, length of relationship, and how long ago the breakup occurred. As with the emotions findings, breakup initiator was what significantly predicted postbreakup behaviors. However, there were very few behaviors that even breakup initiator significantly predicted.

Specifically, contact behaviors such as calling, texting, other online communication, apologizing, and asking for a second chance were all more likely for participants whose ex-partners initiated the breakup. For calling and/or leaving phone messages, participants were $2.71(p<0.001)$ times more likely to engage in this behavior when their expartners initiated the breakup compared to those who indicated that they initiated the breakup or that the decision was mutual $\left(\chi^{2}(4)=35.06, p<0.001\right.$, Nagelkerke $=0.132$ or $13.2 \%$ of variance explained); $78.3 \%$ of cases were classified correctly. Participants were $1.72(p<0.001)$ times more likely to text their ex-partner if the ex-partner was the breakup initiator $\left(\chi^{2}(4)=25.09, p<0.001\right.$, Nagelkerke $=0.083$ or $8.3 \%$ of variance explained); $59.4 \%$ of cases were classified correctly. Participants were $1.87(p<0.001)$ times more likely to contact their ex-partner using online communication methods when 
their ex-partner initiated the breakup $\left(\chi^{2}(4)=23.71, p<0.001\right.$, Nagelkerke $=0.085$ or $8.5 \%$ of variance explained); $73.2 \%$ of cases were classified correctly. For apologizing, it was $1.85(p<0.001)$ times more likely to occur for those whose ex-partner initiated the breakup $\left(\chi^{2}(4)=18.72, p=0.001\right.$, Negelkerke $=0.071$ or $7.1 \%$ of variance explained $)$; $77 \%$ of cases were classified correctly. Lastly, participants were $6.10(p<0.001)$ times more likely to ask for a second chance when their ex-partner initiated the breakup $\left(\chi^{2}(4)=66.37, p<0.001\right.$, Nagelkerke $=0.257$ or $25.7 \%$ of variance explained $)$; $82.4 \%$ of cases classified correctly. Beyond behaviors related to trying to establish direct contact with an ex-partner, one other post-breakup behavior was significantly predicted by initiator. Participants whose ex-partners broke up with them were more likely to try to make their ex-partners jealous $\left(\chi^{2}(4)=14.53, p=0.006\right.$, Nagelkerke $=0.069$ or $6.9 \%$ of variance explained; $87.5 \%$ of cases classified correctly) such that those who were rejected were $1.88(p=0.003)$ times more likely to try to make their exes jealous.

Only two behaviors were significantly predicted by initiator that were more likely to be engaged in by breakup initiators. Being the breakup initiator significantly predicted avoidance of ex-partner $\left(\chi^{2}(4)=41.34, p<0.001\right.$, Nagelkerke $=0.136$ or $13.6 \%$ of variance explained). Specifically, the odds of participants who initiated the breakup avoiding their ex-partner increased by $0.445(p<0.001)$ compared to those who indicated the decision was mutual or that it was initiated by their ex-partner. Additionally, $63.3 \%$ of cases of avoidance or not were classified correctly. The other behavior was establishing a new relationship and breakup initiators were 0.594 $(p=0.007)$ times more likely to do this $\left(\chi^{2}(4)=13.31, p=0.010\right.$, Nagelkerke $=0.068$ or $6.8 \%$ of variance explained; $89.5 \%$ of cases classified correctly).

Additional post-hoc analyses were conducted to determine whether ex-partner characteristics affected post-breakup behaviors as was the case with coping period. It was discovered that the only significant predictor was sense of humor, and this was only among women. Specifically, when examining only women, it was found that for every 1 point increase in the rating of their ex's sense of humor, the odds of women attempting to make in-person contact with their ex increased by 1.36 $(p=0.004)\left(\chi^{2}(1)=10.13, p=0.001\right.$, Negelkerke $=.0 .091$ or $9.1 \%$ of variance explained); $82.9 \%$ of cases were classified correctly). To see general frequencies of these behaviors, refer to Table 2 .

\section{Ex-Partner Effects on Coping Period}

To test hypotheses related to ex-partner characteristics, multinomial regressions for each sex were performed to see whether each characteristic predicted the breakup coping period. Additionally, a multinomial regression including both sexes was conducted to check for interactions between sex and ex-partner characteristics. Post-hoc tests were conducted to see if through multinomial regression coping period could be predicted through characteristics of the self as well as interactions with self characteristics and ex-partner characteristics. As only 5 total multinomial regressions were run, alpha was set at 0.01 to control for multiple comparisons.

In determining what type of regression would be most appropriate, the assumption of proportional odds for the ordinal-level outcome variable of coping period was evaluated using a full likelihood ratio test comparing the residual of the fitted location 
Table 2 Frequencies of post-breakup behaviors

\begin{tabular}{lcc}
\hline & Self (\%) & Ex-partner (\%) \\
\hline Avoidance & 59.3 & 57.3 \\
Calling/leaving phone messages & 20.7 & 29 \\
Texting & 40 & 40 \\
Online communication & 26.3 & 33.4 \\
In-person contact & 16.6 & 23.2 \\
Apologizing & 22 & 31.5 \\
Asking for second chance & 16.8 & 20 \\
Offering gifts & 3.4 & 4.1 \\
Showing off & 6.3 & 9 \\
Continued sexual contact & 8.5 & 10 \\
Spreading rumors & 1.5 & 11.2 \\
Turning mutual friends against ex & 2.4 & 15.9 \\
Making ex jealous & 12.2 & 24.4 \\
Cyberstalking & 5.4 & 4.6 \\
Vandalism/Destroying ex's property & 0.5 & 2.9 \\
Physical aggression & 0.7 & 2.4 \\
Verbal aggression & 2.7 & 12.2 \\
Suicide threats & 2.7 & 2.7 \\
Drinking/Substance abuse & 13.4 & 8.8 \\
Entered new relationship & 10.2 & 24.9 \\
Appearance enhancement & 12.4 & \\
Displaying money/status & 1.7 & \\
\hline & &
\end{tabular}

model to a model with varying location parameters and yielded results significant at alpha of 0.05 . Therefore, coping period was treated as nominal and multinomial regression analyses were conducted instead of ordinal or standard multiple regression. The analyses did not yield the predicted sex differences for ex-partner characteristics, however an unanticipated sex difference did emerge as women were more likely to report a longer coping period for a partner they rated as having a good sense of humor (with all $p$-values $>0.05$ for the other measured characteristics of physical attractiveness, popularity, intelligence, kindness, and ambitiousness). When analyzing the effect of ex-partner sense of humor on coping period among women only, the odds of reporting getting over a breakup in less than 2 weeks compared to the reference category of "never getting over it" significantly decreased by $0.617(p<0.001)$ with every 1 point increase in sense of humor rating $\left(\chi^{2}(5)=19.09, p=0.002\right.$, Nagelkerke $=0.104$, or $10.4 \%$ of variance explained). Further analysis that included both sexes to test for interactions between ex-partner characteristics and sex revealed a similar result. Compared to women, the odds of men reporting getting over an ex-partner in 3-6 months significantly increased by 1.69 for every 1 point increase in ex-partner sense of humor rating $(p=0.004)$ compared to the reference category of "never getting over it" $\left(\chi^{2}\right.$ $(5)=15.06, p=0.010$, Nagelkerke $=0.153$ or $15.3 \%$ of variance explained). When 
examining if coping period based on ex-partner characteristics may be moderated by characteristics of the self, one significant interaction was revealed. For women only, it was found that the more highly they rated their own intelligence, the longer it took them to cope with the breakup of a partner they also rated as intelligent. Specifically, the odds of women getting over an ex-partner under these conditions in 2 weeks or less decreased by $0.958(p=0.004)$ in comparison to the reference category of "will never get over it" $\left(\chi^{2}(5)=12.07, p=0.035\right.$, Nagelkerke $=0.066$ or $6.6 \%$ of variance explained).

Beyond what was originally hypothesized, post-hoc tests were done to see if there were sex differences in characteristics of the self. However, after examining both men and women, none of the measured characteristics of the self significantly predicted breakup coping period.

\section{Discussion}

Many of the predicted sex differences in breakup experiences did not emerge from these data; however, that is not to say that no sex differences existed. The greater propensity of women to initiate breakups was one expected sex difference that was confirmed and was accompanied by an unexpected sex difference in the value of a sense humor (as it was more important for women). Other differences in emotions and behaviors were revealed, however they were at least in some part associated with the factor of breakup initiator. Post-breakup behaviors especially were entirely predicted by initiator rather than by participant gender in a manner that makes intuitive sense. Those who were rejected were more likely to contact their ex via many forms of communication and to ask for a second chance while those who initiated the breakup were more likely to avoid their ex-partner and establish new relationships. The findings that did reveal sex differences are discussed in more detail in the sections that follow.

\section{Breakup Initiation and Post-Breakup Emotions}

For the predictions related to expected sex differences in emotions as a result of a breakup, the only significant sex differences revealed were that men were more likely to report sexual frustration and women were more likely to report happiness. Additionally, these sex differences were mediated by breakup initiator. After further examination into sex differences in propensity to initiate breakups as well as reasons for breakups, it was revealed that while there were no sex differences in reported reasons for breakups (including differences in type of infidelity when appropriate), women were much more likely to initiate breakups than men. This gives added support to the mediation of sex differences in emotions through breakup initiator, as women seemed to be happier as a result of ending a relationship they were most likely unsatisfied with and men seemed to be sexually frustrated as a result of being abandoned by their regular sex partner. This helps clarify the issue of conflicting reports of sex differences in post-breakup emotions (e.g. Perilloux and Buss 2008). Additionally, this finding provides converging evidence for previous research on women's greater propensity to be choosier in the quality of relationship deemed necessary to continue the relationship 
even after initial mate selection (Umberson et al. 2006; Weisfeld et al. 2011) as well as consequent relationship dissolution (Hill et al. 1976; Kalmijn and Poortman 2006; Morris et al. 2015).

\section{Ex-Partner Characteristics: The Value of Humor}

The main ex-partner characteristics that were expected to reveal sex differences in terms of coping period were physical attractiveness and ambition (which was supposed to relate to earning potential) as these are the trait preferences that are the most strongly sexually dimorphic during initial mate selection (Toro-Morn and Sprecher 2003). However, neither of these characteristics had a significant impact on time needed to get over a breakup. Other characteristics measured (although not associated with specific predictions) included intelligence, kindness, and popularity, however only one such characteristic had a significant impact on coping period, and this was sense of humor.

More specifically, it was found that women required a longer coping period for a partner with a good sense of humor. Other post-hoc investigations additionally revealed that for women only, they were more likely to make in-person contact with an expartner that they rated as having a good sense of humor. These results support past research suggesting that a sense of humor in their partner has often been considered more desirable by women than by men (Bressler and Balshine 2006; De Backer et al. 2008; Greengross 2014). The sexual dimorphism in the value of humor as a mate preference fits with parental investment theory. As women's reproductive success is generally increased by a long-term mating strategy due to their increased minimal parental investment, then it would be more important for them to seek a partner who is better able to fulfill the human desire for neophilia over a long span of time (Miller 2001). Conversely, as men's reproductive fitness is generally increased by a short-term mating strategy, many personality characteristics (including a sense of humor) would likely be considered less important than signs of health and fertility such as physical attractiveness (Miller 2001). Even at the more general level of the higher value that women place on personality characteristics, research has found that men are more interested in physical attributes of a partner while women are more interested in aspects of a potential mate's personality including sense of humor, intelligence, and social status (Kenrick et al. 1993). In terms of the ultimate function of women requiring longer to get over an ex-partner with a good sense of humor, one possibility is that missing such a partner could be a way of signaling that a rare, high-quality partner is hard to replace and a better strategy may be to re-establish the relationship. Despite this being self-report data, the fact that women were more likely to make in-person contact with an ex-partner they rated as having a good sense of humor could be viewed as a first step in trying to reconcile the dissolved relationship. This may have been especially more common in ancestral environments consisting of small bands of individuals with few attractive alternatives.

\section{Limitations}

The current study is the first to show preliminary evidence that when women lose a partner with the valuable quality of a good sense of humor, they require a longer coping 
period to deal with the breakup and also make efforts to contact the ex-partner in person. These results show that the longer coping period may function to motivate the re-establishment of a valued relationship; however, the main weakness of this study was that it was not designed in a way that could effectively test this speculation. Another unanswered question due to the design of this study is that even if the function of this increased coping period was to motivate the re-establishment of the dissolved relationship, are such attempts effective? Since this exact question of how ex-partner characteristics affect breakup coping period has never been investigated before (to our knowledge), it was important to first see if ex-partner characteristics did indeed impact coping period, which this study effectively demonstrated. At this point, these findings have laid the foundation for future research to determine the adaptive value of a longer coping period.

This study also has the limitations that come standard with any type of crosssectional, survey study, such as an inability to infer causation and representativeness of the sample. Because this study was conducted online via Mechanical Turk, the problem of missing data is possibly amplified as this is a commonly reported issue with online data collection methods (Denniston et al. 2010). Another issue more specific to this study is that participants' current relationship status is unknown. Some research suggests that one's current relationship status affects the way he or she answers survey questions regarding his or her love life (Spielmann et al. 2013). In this case, perhaps participants distorted their perceptions of their ex-partner's characteristics if they were invested in a new relationship. Derogation of alternatives is common among people in relationships, especially women (Ritter et al. 2010). Another possibility is that those experiencing intense negative emotions due to a very recent breakup may have been experiencing mood-dependent memory (Lewis and Critchley 2003) and rated their expartners more negatively than they would have otherwise. However, this explanation is unlikely as length of time that elapsed since the breakup did not significantly affect any outcome variables.

\section{Future Directions}

Since the loss of a partner with a good sense of humor had the biggest impact on breakup coping period for women, a good avenue for future research would be to investigate what function this increased coping period serves. In terms of post-breakup behaviors, the current study has shown that losing a partner with a good sense of humor leads women to attempt in-person contact with the ex-partner which may lead to the prediction that this greater upset over the relationship motivates the individual to reestablish the relationship. However, at this time it is not known whether such attempts at contact actually result in re-establishment of the relationship. Perhaps a longitudinal design could track the outcomes of post-breakup attempts at contact to see if they lead to reconciliation. Additionally, future work could add an item inquiring about current relationship status to the Relationship Dissolution Questionnaire in order to see how that affects self-reported post-breakup emotions and behaviors.

Even though length of time that elapsed since the breakup did not affect self-report answers, it should be noted that only $1.5 \%$ of participants reported the breakup occurring less than 1 week ago and only $6.6 \%$ reported a breakup occurring less than 1 month ago. The majority of participants reported a breakup occurring 1-2 years ago. 
Therefore, it is possible that this sample was not representative in capturing the experiences of people in the midst of actual breakup coping. Therefore, it may be useful to recruit a sample of participants who experienced a breakup a month ago or less and a separate, equal size sample of those who experienced their most recent breakup 1-2 years ago to compare the self-report answers of the two samples.

\section{Conclusion}

This study was conducted in order to expand upon the limited literature on nonmarital breakups from an evolutionary perspective. The intention was not only to replicate and/ or clarify the findings from Perilloux and Buss (2008) but also to add the element of expartner characteristics on breakup experiences to see if such characteristics are as important during relationship dissolution as they are in relationship formation. Sex differences in likelihood of initiating breakups and sex differences in post-breakup emotions were revealed in a manner consistent with greater female choosiness (and past research). However, the most novel finding that goes beyond the existing literature was that women indicated requiring a longer period to cope with a breakup from a partner with a good sense of humor as well as making attempts to make in-person contact with such an ex-partner. This leaves the need for further research into this phenomenon using more sophisticated research methods to better understand the ultimate function of this reaction to a breakup.

\section{References}

Archer, J. (2000). Sex differences in physical aggression to partners: a reply to frieze (2000), O'Leary (2000), and white, smith, Koss, and figueredo (2000). Psychological Bulletin, 126, 697-702. doi:10.1037//00332909.126.5.697.

Baron, R. M., \& Kenny, D. A. (1986). The moderator-mediator variable distinction in social psychological research: Conceptual, strategic, and statistical considerations. Journal of Personality and Social Psychology, 51, 1173. doi:10.1037/0022-3514.51.6.1173.

Battaglia, D. M., Richard, F. D., Datteri, D. L., \& Lord, C. G. (1998). Breaking up is (relatively) easy to do: a script for the dissolution of close relationships. Journal of Social and Personal Relationships, 15(6), 829845. doi: $10.1177 / 0265407598156007$.

Baumeister, R. F., Catanese, K. R., \& Vohs, K. D. (2001). Is there a gender difference in strength of sex drive? Theoretical views, conceptual distinctions, and a review of relevant evidence. Personality and Social Psychology Review, 5, 242-273. doi:10.1207/S15327957PSPR0503_5.

Baxter, L. A. (1986). Gender differences in the hetero-sexual relationship rules embedded in break-up accounts. Journal of Social and Personal Relationships, 3, 289-306. doi:10.1177/0265407586033003.

Bressler, E. R., \& Balshine, S. (2006). The influence of humor on desirability. Evolution and Human Behavior, 27, 29-39. doi:10.1016/j.evolhumbehav.2005.06.002.

Buchanan, C. M., Maccoby, E. E., \& Dornbusch, S. M. (1996). Adolescents after divorce. Cambridge: Harvard University Press.

Buss, D. M. (1989). Sex differences in human mate preferences: Evolutionary hypotheses tested in 37 cultures. Behavioral and brain sciences, 12, 1-49. doi:10.1017/S0140525X00023992.

Buss, D. M. (2002). Human mate guarding. Neuroendocrinology Letters, 23(Suppl 4), $23-29$.

Buss, D. M., \& Schmitt, D. P. (1993). Sexual strategies theory: an evolutionary perspective on human mating. Psychological Review, 100(2), 204. doi:10.1037/0033-295X.100.2.204.

Buss, D. M., \& Shackelford, T. K. (1997). From vigilance to violence: mate retention tactics in married couples. Journal of Personality and Social Psychology, 72(2), 346. doi:10.1037/0022-3514.72.2.346. 
Buss, D. M., Shackelford, T. K., Kirkpatrick, L. A., \& Larsen, R. J. (2001). A half century of mate preferences: the cultural evolution of values. Journal of Marriage and Family, 63, 491-503. doi:10.1111/j.1741-3737. 2001.00491.x.

Casler, K., Bickel, L., \& Hackett, E. (2013). Separate but equal? A comparison of participants and data gathered via Amazon's MTurk, social media, and face-to-face behavioral testing. Computers in Human Behavior, 29, 2156-2160. doi:10.1016/j.chb.2013.05.009.

Cherlin, A. J., Furstenberg Jr., F. F., Chase-Lansdale, L., Kiernan, K. E., Robins, P. K., Morrison, D. R., et al. (1991). Longitudinal studies of effects of divorce on children in Great Britain and the United States. Science, 252, 1386-1389. doi:10.1126/science.2047851.

Daly, M., \& Wilson, M. (1988). Homicide. New Brunswick: Transaction Books.

De Backer, C., Braeckman, J., \& Farinpour, L. (2008). Mating intelligence in personal ads. In G. Geher, \& G. Miller (Eds.), Mating intelligence: Sex, relationships, and the mind's reproductive system (pp. 77-101). Mahwah: Lawrence Erlbaum Associates Publishers.

Denniston, M. M., Brener, N. D., Kann, L., Eaton, D. K., McManus, T., Kyle, T. M., et al. (2010). Comparison of paper-and-pencil versus web administration of the youth risk behavior survey (YRBS): participation, data quality, and perceived privacy and anonymity. Computers in Human Behavior, 26, 1054-1060. doi: 10.1177/0193841X10362491.

Dillman, D. A. (2007). Mail and internet surveys: The tailored design method (2nd ed., ). Hoboken: Wiley.

Duntley, J. D., \& Buss, D. M. (2012). The evolution of stalking. Sex Roles, 66, 311-327. doi:10.1007/s11199010-9832-0.

Field, T. (2011). Romantic breakups, heartbreak and bereavement-romantic breakups. Psychology, 2, 382387. doi:10.4236/psych.2011.24060.

Field, T., Diego, M., Pelaez, M., Deeds, O., \& Delgado, J. (2010). Breakup distress and loss of intimacy in university students. Psychology, 1, 173-177. doi:10.4236/psych.2010.13023.

Fisher, H. (2004). Dumped! New Scientist, 181, 40-43.

Gottman, J. M. (1994). What predicts divorce?: The relationship between marital processes and marital outcomes: john Mordechai gottman. Routledge.

Grammer, K., Renninger, L., \& Fischer, B. (2004). Disco clothing, female sexual motivation, and relationship status: is she dressed to impress? Journal of Sex Research, 41, 66-74. doi:10.1080/00224490409552214.

Greengross, G. (2014). Male production of humor produced by sexually selected psychological adaptations. In V. A. Weekes-Shackelford, T. K. Shackelford, V. A. Weekes-Shackelford, \& T. K. Shackelford (Eds.), Evolutionary perspectives on human sexual psychology and behavior (pp. 173-196). New York: Springer Science + Business Media. doi:10.1007/978-1-4939-0314-6_9.

Guéguen, N., \& Lamy, L. (2012). Men's social status and attractiveness. Swiss Journal of Psychology, 71, 157-160. doi:10.1024/1421-0185/a000083.

Haselton, M. G., \& Gangestad, S. W. (2006). Conditional expression of women's desires and men's mate guarding across the ovulatory cycle. Hormones and Behavior, 49, 509-518. doi:10.1016/j.yhbeh.2005. 10.006.

Hill, C. T., Rubin, Z., \& Peplau, L. A. (1976). Breakups before marriage: the end of 103 affairs. Journal of Social Issues, 32, 147-168. doi:10.1111/j.1540-4560.1976.tb02485.x.

Janssens, K., Pandelaere, M., Van den Bergh, B., Millet, K., Lens, I., \& Roe, K. (2011). Can buy me love: mate attraction goals lead to perceptual readiness for status products. Journal of Experimental Social Psychology, 47, 254-258. doi:10.1016/j.jesp.2010.08.009.

Johnson, D. P., \& Whisman, M. A. (2013). Gender differences in rumination: a meta-analysis. Personality and Individual Differences, 55, 367-374. doi:10.1016/j.paid.2013.03.019.

Kalmijn, M., \& Poortman, A. R. (2006). His or her divorce? The gendered nature of divorce and its determinants. European Sociological Review, 22, 201-214. doi:10.1093/esr/jci052.

Kenrick, D. T., Groth, G. E., Trost, M. R., \& Sadalla, E. K. (1993). Integrating evolutionary and social exchange perspectives on relationships: effects of gender, self-appraisal, and involvement level on mate selection criteria. Journal of Personality and Social Psychology, 64, 951-969. doi:10.1037/ 0022-3514.64.6.951.

Lavner, J. A., \& Bradbury, T. N. (2012). Why do even satisfied newlyweds eventually go on to divorce? Journal of Family Psychology, 26, 1-10. doi:10.1037/a0025966.

Le, B., Dove, N. L., Agnew, C. R., Korn, M. S., \& Mutso, A. A. (2010). Predicting nonmarital romantic relationship dissolution: a meta-analytic synthesis. Personal Relationships, 17, 377-390. doi:10.1111/j. 1475-6811.2010.01285.x.

Lewis, P. A., \& Critchley, H. D. (2003). Mood-dependent memory. Trends in Cognitive Sciences, 7, 431-433. doi:10.1016/j.tics.2003.08.005. 
Miller, G. (2001). The mating mind: How sexual choice shaped the evolution of human nature. New York: Anchor Books.

Morris, C. E., Reiber, C., \& Roman, E. (2015). Quantitative sex differences in response to the dissolution of a romantic relationship. Evolutionary Behavioral Sciences, 9, 270-282. doi:10.1037/ebs0000054.

Perilloux, C., \& Buss, D. M. (2008). Breaking up romantic relationships: costs experienced and coping strategies deployed. Evolutionary Psychology, 6, 164-181.

Preacher, K. J., \& Hayes, A. F. (2004). SPSS and SAS procedures for estimating indirect effects in simple mediation models. Behavior Research Methods, Instruments, \& Computers, 36, 717-731.

Ritter, S. M., Karremans, J. C., \& van Schie, H. T. (2010). The role of self-regulation in derogating attractive alternatives. Journal of Experimental Social Psychology, 46, 631-637. doi:10.1016/j.jesp.2010.02.010.

Rubin, Z., Peplau, L. A., \& Hill, C. T. (1981). Loving and leaving: sex differences in romantic attachments. Sex Roles, 7, 821-835. doi:10.1007/BF00287767.

Schmitt, D. P., Shackelford, T. K., Duntley, J., Tooke, W., \& Buss, D. M. (2001). The desire for sexual variety as a key to understanding basic human mating strategies. Personal Relationships, 8, 425-455. doi:10. 1111/j.1475-6811.2001.tb00049.x.

Shackelford, T. K., Buss, D. M., \& Bennett, K. (2002). Forgiveness or breakup: sex differences in responses to a partner's infidelity. Cognition \& Emotion, 16, 299-307. doi:10.1080/02699930143000202.

Spielmann, S. S., MacDonald, G., Maxwell, J. A., Joel, S., Peragine, D., Muise, A., et al. (2013). Settling for less out of fear of being single. Journal of Personality and Social Psychology, 105, 1049-1073. doi:10. 1037/a0034628.

Spitzberg, B. H., \& Hoobler, G. (2002). Cyberstalking and the technologies of interpersonal terrorism. New Media \& Society, 4, 71-92. doi:10.1177/14614440222226271.

Spitzberg, B. H., Cupach, W. R., \& Ciceraro, L. D. (2010). Sex differences in stalking and obsessive relational intrusion: Two meta-analyses. Partner Abuse, 1, 259-285. doi:10.1891/1946-6560.1.3.259.

Tjaden, P., \& Thoennes, N. (1998). Stalking in America: Findings from the National Violence Against Women Survey. Washington, DC: U.S. Department of Justice, National Institute of Justice, NCJ 169592.U.S.

Todd, P. M., Penke, L., Fasolo, B., \& Lenton, A. P. (2007). Different cognitive processes underlie human mate choices and mate preferences. Proceedings of the National Academy of Sciences, 104, 15011-15016. doi: 10.1073/pnas.0705290104.

Toro-Morn, M., \& Sprecher, S. (2003). A cross-cultural comparison of mate preferences among university students: The United States vs. the People's Republic of China (PRC). Journal of Comparative Family Studies, 34, 151-170 http://www.jstor.org/stable/41603870.

Trivers, R. L. (1972). Parental investment and sexual selection. In B. Campbell (Ed.), Sexual selection and the descent of man (pp. 1871-1971). Chicago: Aldine.

Umberson, D., Williams, K., Powers, D. A., Liu, H., \& Needham, B. (2006). You make me sick: marital quality and health over the life course. Journal of Health and Social Behavior, 47, 1-16. doi:10.1177/ 002214650604700101.

Valentine, K. A., Li, N. P., Penke, L., \& Perrett, D. I. (2014). Judging a man by the width of his face: the role of facial ratios and dominance in mate choice at speed-dating events. Psychological Science, 25, 806-811. doi:10.1177/0956797613511823.

Von Rueden, C., Gurven, M., \& Kaplan, H. (2010). Why do men seek status? Fitness payoffs to dominance and prestige. Proceedings of the Royal Society of London B: Biological Sciences, 278(1715). doi:10.1098/ rspb.2010.2145.

Wallerstein, J., Lewis, J., \& Packer Rosenthal, S. (2013). Mothers and their children after divorce: report from a 25-year longitudinal study. Psychoanalytic Psychology, 30, 167-187. doi:10.1037/a0032511.

Weisfeld, C. C., Dillon, L. M., Nowak, N. T., Mims, K. R., Weisfeld, G. E., Imamoglu, E. O., et al. (2011). Sex differences and similarities in married couples: patterns across and within cultures. Archives of Sexual Behavior, 40, 1165-1172. doi:10.1007/s10508-011-9790-9.

Williams, S. L., \& Frieze, I. H. (2005). Courtship behaviors, relationship violence, and breakup persistence in college men and women. Psychology of Women Quarterly, 29, 248-257. doi:10.1111/j.1471-6402. 2005.00219.x.

Woodward, K., \& Richards, M. H. (2005). The parental investment model and minimum mate choice criteria in humans. Behavioral Ecology, 16, 57-61. doi:10.1093/beheco/arh121. 